\title{
Value Co-creation with Stake
Using Action Research as a Meta-methodology in a Funded Research Project
}

Bob Dick, Independent Scholar, Chapel Hill, Queensland, Australia

Shankar Sankaran, Professor Organisational Project Management, University of Technology

Sydney, Australia

Kelly Shaw, Director, KP Health, Melbourne, Victoria, Australia

Jacqueline Kelly, Chief Executive Officer, Lutheran Community Care, Milton, Queensland,

Australia

Jeffrey Soar, Professor, University of Southern Queensland, Toowoomba, Queensland, Australia

Alan Davies, Emeritus Professor, Southern Cross University, Lismore, New South Wales,

Australia

Annie Banbury, Project Manager and Research Scholar, Southern Cross University, Lismore,

New South Wales, Australia

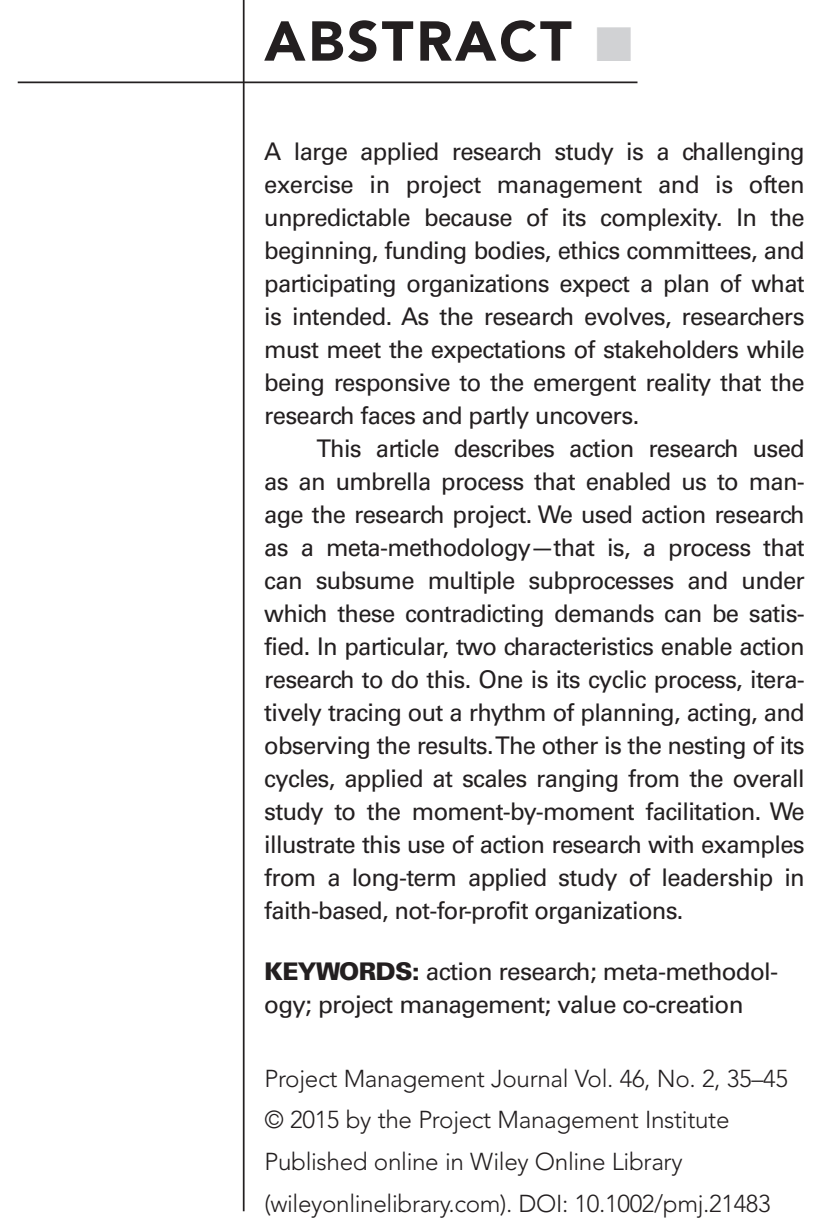

\section{INTRODUCTION}

he aim of this article is to describe how action research can be used as a flexible approach to the collaborative project management of a research project. In the article we outline the context of a recent research situation, and describe the characteristics of action research as a meta-methodology. We explain two features of action research that can provide flexibility within a planned process: an iterative cycle of planning, action, and reflection, and the use of nested cycles that can be applied at any scale. We illustrate the use of action research as a meta-methodology with examples from the research project.

When complex projects require project management, agile methods are often used. Guindon (1990) explained that top-down methods had increasingly been abandoned by experienced software designers in favor of agile approaches. Now project managers are beginning to export agile methods from software development into other applications of project management, as White (2014) explains. Project managers seeking to do this may find relevance in some of the action research strategies reported below.

Our intention therefore is not to present a conventional research report on the study, which has been reported elsewhere (Cartwright et al., 2013). Instead, we explain the sources of flexibility in action research. Aspects of the research study are used only to illustrate such sources. The article is structured accordingly. We begin with a description of the context in which the study took place. A description of the action research process then follows, identifying iterative cycles and their nesting as important contributions to flexibility. Finally, the way in which we used action research to manage the complexity of the research is explained, with examples. As is typical in action research, the literature is cited where it is relevant, rather than in a separate literature review. 
Value Co-creation with Stakeholders Using Action Research as a Meta-methodology in a Funded Research Project

\section{Context}

Aged and community care is a growing sector associated with rapidly aging populations around the world (OECD, 2005). Population aging is seen to be driving increasing demands for aged and community care services (Institute of Medicine, 2001). Not-for-profit organizations are major providers of aged and community care in many countries (Wiener et al., 2007). Heightened demand for services, combined with workforce shortages, increasing competition with other providers, constrained government support, and complex regulatory requirements are undermining the operational capacity and financial viability of many organizations (Pietroburgo \& Wernet, 2010). In order to respond to these challenges, high quality leadership of aged and community care not-for-profits is required.

Senior managers in not-for-profits are expected to achieve the dual (often opposing) goals of producing good financial results while meeting the organization's social aspirations, and are frequently bound by government regulations while at the same time being exposed to market forces. Competing ideologies add their own complexity, with some scholars arguing for strong, identifiable leaders, and others claiming that what is needed is "communities where everyone shares the experience of serving as a leader, not serially, but concurrently and collectively" (Raelin, 2004, p. 5).

The project described in this article was the first study of its kind in Australia to create a leadership capability framework for not-for-profits. In this research "leadership" is defined as a capability that goes beyond the standard parameters of operational management and that includes a strategic capacity as well as difficult-to-define attributes such as innovation and vision, and a justified confidence in their ability to use those attributes in their organizational role.

Organizations participating in this research included three universitiesSouthern Cross University, University of Technology Sydney, and University of Southern Queensland, as well as two large faith-based, not-for-profit organizations-Lutheran Community Care, Queensland (LCC) and Baptist Community Services (BCS), which provide aged care and community care.

LCC, a faith-based Australian notfor-profit, is "one of Queensland's largest providers of aged care, family services, disability services, and hospital chaplaincy" (http://lccqld.org.au/history). It operates more than 30 service facilities in urban and regional Queensland and employs more than 1,000 staff members and volunteers; it operates retirement communities, nursing homes, community care, and day respite centers.

BCS is "a leading not-for-profit Christian care organization that has been serving the aged and people living with disadvantage for the past 65 years" (http://www.bcs.org.au/AboutBCS .aspx) and employs more than 3,600 staff members and has 1,000 volunteers. It runs more than 160 facilities under two operating divisions-BCS AgeCare and BCS LifeCare.

We were a diverse research team brought together from the three universities and two industry partners. Our research topic was leadership in faith-based, not-for-profit organizations. A previous pilot study with LCC (Cartwright, Sankaran, \& Kelly, 2008) had given us a theoretical leadership framework. Our intention was to further develop that framework to produce actionable theory. We wanted the outcomes of the study to be useful for the industry partners, and at the same time contribute to theory.

For the purpose of triangulation (the combined use of several different research approaches) and therefore more rigorous research, we planned multiple ways of collecting and analyzing relevant data. We sought a coherent integration of the multiple data sources and methods, and the literature. As we also desired a dual practical and academic end product, our chosen overall approach was action research.
Informed by the work of authors, including Phelps and Graham (2010), we regarded the complexity of the situation as further justification for our choice of action research. It has been known, at least since the work of Lorenz (1972), that sufficiently complex systems can be inherently unpredictable. We think that certain features of action research, discussed below, provide flexibility and enable researchers to deal with the unpredictability of complex situations. The situation we faced as a research team was complex in several respects: a diverse and changing team, varied research situations, and a convoluted research topic.

Members of the team were drawn from different organizations and with backgrounds in different disciplines. Some of us were academics, some practitioner-academics, and some practitioners. The research team included senior managers from the two industry partners. Both industry partners are large and diverse organizations in the aged and community care sector. Most members of the research team regularly faced other external demands that impacted on their involvement in the leadership research study.

The research situation consisted of the two different organizations, augmented occasionally with people from other organizations in the aged and community care sector. In the processes we used during the research program, we sought to involve participants from these organizations as more than mere subjects of research. We invited them to be partners who joined us in interpreting the information they provided and drawing conclusions from it. When compiling a sample for some element of the research, we aimed for diversity, with participants at varying levels of management and from different organizational functions. In other words, the industry partners-and for that matter, each sample of participants-comprised what Peter Checkland (1981 and elsewhere) calls "human activity systems" complex and inherently hard to predict. 
The research topic of leadership in faith-based not-for-profit organizations does not lend itself to precise formulation. Leadership itself is a complex topic, and is increasingly analyzed from the perspective of complexity theory (Lichtenstein, Uhl-Bien, Marion, Seers, Orton, \& Schreiber, 2006; Remington, 2011). Our interest was not only in leadership as in the behavior of leaders, but (increasingly as the research progressed) also in leadership as the tota means by which the people in an organization achieve desired organizational outcomes. We intended our research to be relevant, not only to the present but also to an uncertain future.

\section{The Process of Action Research}

In our use of action research we drew on a feature of it that, in some respects, is currently underreported and undervalued-its ability to function as an umbrella process, a meta-methodology, under which a variety of flexible methods can be assimilated. In the current literature action research is now often regarded as an "orientation to inquiry," in the words of Reason and Bradbury (2008, p. 1). Key aspects of that orientation are that participants are involved and treated as equals, and that the resulting knowledge is actionable. Action research is collaborative (Denis \& Lehoux, 2009). Without wishing to deny the relevance and importance of that orientation, we would add that the complexity of human systems also demands flexibility.

An important source of the flexibility is the process that action research uses. Two aspects of this process in particular help it to function as a flexible metamethodology. The first, consisting of an iterative cycle, is common in the action research literature, though we believe its contribution as a metaprocess is less often acknowledged. The other is that the cycles may be nested to provide cycles within cycles, to almost any depth. Flexibility is thus further and substantially enhanced. These two aspects, the iterative cycles, and their ability to be nested, are addressed further below.

\section{Iterative Cycles}

In almost all forms of action research, an iterative cycle is a prominent aspect. It was evident in the earliest formulations of action research. Lewin (1946, p. 38) described it as "a spiral of steps, each of which is composed of a circle of planning, action, and fact-finding about the result of the action." Susman and Evered (1978), in their much-cited paper, describe a five-element cycle: diagnosing, action planning, action taking, evaluating, and specifying learning. A much-used formulation is that of Kemmis and McTaggart (e.g., 2005): plan, act, observe, and reflect, although in their later writing (Kemmis, McTaggart, \& Nixon, 2014) they have displaced this cycle from its central position.

The cycle has a widespread existence beyond action research. It is a natural and logical way of responding to a complex and therefore uncertain situation that requires action. Faced with such a situation, people are likely first to try to reach a tentative understanding of the situation and to develop a set of goals. They then devise actions to achieve those goals, and enact them. They then review the results and draw conclusions from them. If the goals are not fully achieved, they may revise the actions and repeat the cycle. It is of note that a very similar iterative process is to be found in other areas, such as experiential learning (e.g., Kolb, 1984), continuous improvement (e.g., Deming, 1986), and evaluation (e.g., Patton, 2011). These are elaborations of a basic cycle, which alternates between action and the review of that action.

The importance of the basic cycle of planning, acting, and reviewing is that it provides great flexibility. It allows trial and error to be informed by experience. When the situation is uncertain or unpredictable, the cycle can be repeated, with varied plans and actions, until success is achieved. The variation can be guided by observation of what works and what does not.

We can therefore develop our understanding of a target system by attempting to intervene in it. As Schein
(1996, p. 34) says, "You cannot understand a system until you try to change it," attributing the saying to Kurt Lewin. For example, the intended goals may be varied progressively as intervention produces increased understanding. The variation may take the form of substituting a method that now seems more promising for another that did not work as planned. Additional participants may be involved in a study as their relevance as stakeholders becomes apparent.

The above considerations have implications for the use of literature. Action research often begins with a concern or problem rather than a gap in the literature and a research hypothesis. Often, therefore, the relevant literature is not obvious in the beginning of a study. It becomes evident as the study develops. Davis (2004) and Fisher and Phelps (2006) make a similar point. It may be more appropriate to review the literature as and when it is required.

\section{Nested Cycles}

The ability of the iterative cycles to be nested is less often noted, although it is probably common in practice. In other words, the cycles can be applied at different scales. Nested cycles have been described as a characteristic of software development projects, for example, by Edson (2012). There has been some acknowledgment by List (2006), in futures studies, of the benefits of nested cycles. An overall study may comprise an action research cycle, as may each major element, and so on down to the moment-by-moment facilitation of a data-gathering or other process. At each depth of cycle, actions can be adjusted in response to the new understanding that the action uncovers. Figure 1 summarizes a simple form of the nested cycles.

Thus, the design for an overall study may be based on a previous study. Each study in a sequence of studies may then comprise one action research cycle. In the review phase of a previous study, some conclusions may be drawn-for example, about what worked as expected, and what did not. In planning a subse- 
Value Co-creation with Stakeholders Using Action Research as a Meta-methodology in a Funded Research Project

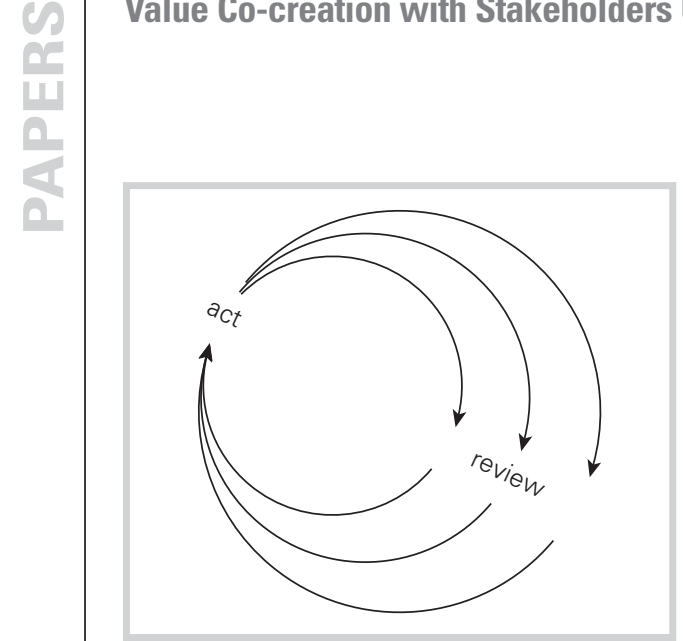

Figure 1: Action research cycles may be nested.

quent study, the review of the first study can be taken into account. The second study can then be modified accordingly.

If an action research project includes a sequence of components, as many do, each component can itself be treated as an action research cycle. The review of each cycle yields improved understanding about the situation and perhaps about the processes used. That understanding then permits better planning and implementation of subsequent components of the study.

Further, many of the processes that form part of a large action research study are themselves iterative. Processes such as the convergent interviewing (Dick, 1990) used in our pilot study, and Delphi (Delbecq, Van de Ven, \& Gustafson, 1986) used in several places in our research, are explicitly and intentionally iterative. Less explicitly, other processes frequently alternate the collection of information and its interpretation.

We can use our own leadership study as an example. The major study summarized below can be regarded overall as a cycle. It arose out of reflection on the earlier pilot study, also a cycle. It is potentially to be followed by additional cycles of research that explore issues so far unresolved. The pilot study informed detailed planning for a grant application to be formulated. Each of its major components, though previously planned, was elaborated in greater detail immediately before implementation, taking into account the prior elements of the study. This more elaborate plan, in turn, was adjusted during implementation in response to the emerging situation. The facilitators of our workshops were people with the necessary experience, skills, and ability to respond in the moment to what occurred.

Community-based participatory research provides further examples of how several processes can be subsumed within a single action research project. A mixed-methods approach combining qualitative and quantitative components is not unusual. Community participants and researchers work together in the style of participatory action research to decide on goals and plan research components. Recent examples include Lingard, Albert, and Levinson (2013) and Windsor (2013). Many action research theses and dissertations have multiple phases, often using different methods within each phase (Sankaran \& Kumar, 2010). Zuber-Skerritt and Perry (2002) recommend as much.

\section{Managing a Research Project}

We are therefore treating action research as a useful process for project management, allowing multiple approaches to be assembled into a single coherent study. There does not seem to be an agreed-on term for this important function; that action research has such a function is recognized. Burns (2007, p. 179) calls action research "a hub or container for a variety of methods." Greenwood and Levin (2006, p. 89) describe action research as a "research strategy ... that orchestrates the overall research process in a distinctive way." Of participatory research, Macaulay, Jagosh, Pluye, Bush, and Salsberg (2013, p. 159) say that it is "not a research methodology" but an approach that allows mixed methods. We read this as consistent with our view that action research is an umbrella process under which several components can be sequenced and integrated.

However, the term "metamethodology" we use here does have some currency. Attwater (2014), for example, has an article using that term in the SAGE Encyclopedia of Action Research. The label "meta-methodology" has been used in a similar sense in a variety of fields, including research into religious fundamentalism (Haynes, 2010), methods design (Peon-Escalante, Aceves, \& Badillo, 2008), public relations (Rampton \& Stauber, 2002), and software quality assurance (Bhargava, 2013), among others. Jackson (2003, p. 285) captures a similar meaning when he says of total systems intervention (TSI): "because it organizes and employs other systems methodologies, TSI should strictly be described as a metamethodology."

\section{The Research Project}

The research project we conducted consisted of two major phases, a pilot study (Cartwright et al., 2008) conducted over approximately one year, followed by a three-year study funded by the Australian Research Council (ARC). Following we provide an overview of the components of both phases of the study, and then (in somewhat more detail) the components. Figure 2 shows the study (both pilot and main) in overview. We later explain the contribution of the cyclic and nested process to the study.

The pilot study was conducted by a partnership between one university and one industry partner, a faith-based, notfor-profit organization; two workshops and 18 in-depth interviews were drawn upon to derive a leadership framework. The components, and their rationales, are briefly described in Table 1. This pilot study then provided the basis for preparing an application for a threeyear ARC Linkage Grant (awarded by the Australian Government to support research and development projects that involve collaboration between academic researchers and practitioners in the industry).

For the major study the research team was expanded; it then comprised representatives from three universities and two industry partners. The aim of 
the main study remained as before: to develop actionable theory about leadership in faith-based, not-for-profit organizations, with the related intention of testing and further extending and refining the leadership framework developed in the pilot study.

The application for the research grant outlined the intended overall research project. For more detailed planning and for obtaining ethics approval, each of the three years of the study was further developed as necessary. The ethics approval process was not very complex, because the ethics approval given by the administering university was accepted for a simple approval by the other two universities. Each university provided an ethics authorization number for the research to be carried out by the investigator from that university. In addition, in the spirit of action research, we refined each project component in turn in yet more detail. The Year 1 components of the main study

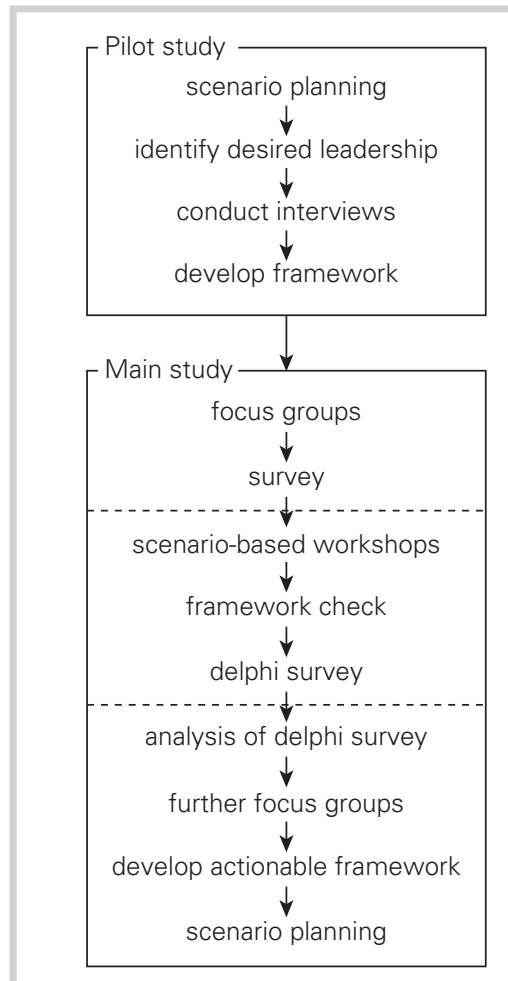

Figure 2: The overall study: Pilot study and three-year main study. consisted of a focus group with each industry partner and an email survey of a stratified random sample of chief executives in the aged and community care sector. Table 2 summarizes the Year 1 components and their rationales.

Year 2 of the project began with four scenario-based workshops, two for samples of managers at each industry partner. The aged and community care sector faced substantial change, and senior managers from each industry partner developed realistic and challenging near-future scenarios. Near the end of each workshop, the leadership framework previously developed was described, and participants were asked to critique it. The year concluded with the conduct of a substantial two-stage Delphi survey, primarily within the industry partners. Participants were asked a series of questions about the leadership capabilities required in faith-based, not-for-profit organizations, and ways of acquiring those capabilities. Table 3 briefly describes these components and their rationales.

In the final year of the project, the results of the email Delphi were analyzed in detail. Two half-day focus groups were conducted, one with each industry partner, to explore further some of the key

\begin{tabular}{|c|c|c|}
\hline Component & Brief Description & Rationale \\
\hline Workshop 1 & $\begin{array}{l}\text { Scenario planning to define } \\
\text { possible futures } \\
\text { A two-phase email Delphi } \\
\text { followed by a half-day workshop }\end{array}$ & $\begin{array}{l}\text { Email Delphi to reduce face-to-face time } \\
\text { for participants } \\
\text { Multiple scenarios so that leadership } \\
\text { capabilities identified are likely to be } \\
\text { relevant to dealing with the unexpected }\end{array}$ \\
\hline Workshop 2 & $\begin{array}{l}\text { To identify leadership required } \\
\text { by the four scenarios } \\
\text { A two-phase email Delphi } \\
\text { followed by a half-day workshop }\end{array}$ & $\begin{array}{l}\text { Study purpose was to define capabilities, } \\
\text { capacities, and personal attributes required } \\
\text { in the future by leaders in faith-based, } \\
\text { not-for-profit organizations }\end{array}$ \\
\hline Interviews & $\begin{array}{l}18 \text { in-depth interviews using } \\
\text { convergent interviewing }\end{array}$ & To triangulate findings from workshops \\
\hline Framework & $\begin{array}{l}\text { Research team collated material } \\
\text { from workshops and interviews }\end{array}$ & $\begin{array}{l}\text { To convert data into an actionable leadership } \\
\text { framework for faith-based, not-for-profits }\end{array}$ \\
\hline
\end{tabular}

Table 1: The components of the pilot study and their rationales.

\begin{tabular}{|c|c|c|}
\hline Component & Brief Description & Rationale \\
\hline \multicolumn{3}{|c|}{ The main study involved three universities and two faith-based, not-for-profit organizations } \\
\hline $\begin{array}{l}\text { Focus } \\
\text { groups }\end{array}$ & $\begin{array}{l}\text { One focus group with each of the two } \\
\text { industry partners } \\
\text { Participants defined a vision for their } \\
\text { faith-based, not-for-profit and identi- } \\
\text { fied present leadership capabilities } \\
\text { and the capabilities required to lead } \\
\text { faith-based, not-for-profits in this } \\
\text { environment }\end{array}$ & $\begin{array}{l}\text { To extend results beyond the single } \\
\text { faith-based, not-for-profit of the pilot } \\
\text { study } \\
\text { For participants to identify desirable } \\
\text { future leadership capabilities while } \\
\text { remaining anchored to some extent to } \\
\text { the reality of their present organization }\end{array}$ \\
\hline Survey & $\begin{array}{l}\text { Email survey of a stratified random } \\
\text { sample of CEOs in the aged and } \\
\text { community care sector, with a request } \\
\text { that they distribute it to senior } \\
\text { managers and board chair }\end{array}$ & $\begin{array}{l}\text { To triangulate the focus group results } \\
\text { and generalize them to other aged and } \\
\text { community care organizations beyond } \\
\text { the two industry partner faith-based, } \\
\text { not-for-profits }\end{array}$ \\
\hline
\end{tabular}


Value Co-creation with Stakeholders Using Action Research as a Meta-methodology in a Funded Research Project

\begin{tabular}{|c|c|c|}
\hline Component & Brief Description & Rationale \\
\hline \multicolumn{3}{|c|}{$\begin{array}{l}\text { Main study, year } 2 \\
\text { The main study involved three universities and two faith-based, not-for-profit (FBNFP) organizations }\end{array}$} \\
\hline $\begin{array}{l}\text { Scenario-based } \\
\text { workshops }\end{array}$ & $\begin{array}{l}\text { In small groups, participants at four workshops } \\
\text { (two for each faith-based, not-for-profit) considered } \\
\text { a likely near-future scenario chosen by their senior } \\
\text { management as realistic and challenging, to identify } \\
\text { required leadership capabilities. All four scenarios involved } \\
\text { managing change. }\end{array}$ & $\begin{array}{l}\text { To collect realistic data different from data so far collected. } \\
\text { To triangulate with data from pilot study and Year } 1 \\
\text { components of the main study. } \\
\text { As the two industry partners faced change, to ensure that } \\
\text { capabilities for managing change were included. }\end{array}$ \\
\hline $\begin{array}{l}\text { Framework } \\
\text { check }\end{array}$ & $\begin{array}{l}\text { As part of each scenario-based workshop (above), participants } \\
\text { were asked to comment on the adequacy, usefulness, and } \\
\text { completeness of the framework developed in the pilot study. }\end{array}$ & $\begin{array}{l}\text { To further refine the framework. To test it against the } \\
\text { perceptions of managers from the industry partners after } \\
\text { they had been reflecting on required leadership capabilities. }\end{array}$ \\
\hline Delphi survey & $\begin{array}{l}\text { A two-stage email Delphi process was used to collect data } \\
\text { from industry partner managers in response to questions } \\
\text { about present and required leadership capabilities and ways } \\
\text { of acquiring those capabilities. }\end{array}$ & $\begin{array}{l}\text { To collect data on differences between not-for-profits, } \\
\text { faith-based organizations, and other organizations. } \\
\text { To augment the Year } 1 \text { survey because of that survey's } \\
\text { relatively poor response rate. }\end{array}$ \\
\hline
\end{tabular}

\begin{tabular}{l|l|l|}
$\begin{array}{l}\text { Component } \\
\begin{array}{l}\text { Delphi } \\
\text { analysis }\end{array}\end{array}$ & \multicolumn{1}{|c}{ Brief Description } & \multicolumn{1}{c|}{ Rationale } \\
$\begin{array}{l}\text { Focus } \\
\text { groups }\end{array}$ & $\begin{array}{l}\text { Two half-day workshops, one with senior } \\
\text { managers from each industry partner, } \\
\text { explored details of some of the previous } \\
\text { results }\end{array}$ & $\begin{array}{l}\text { To explore finer differences } \\
\text { between industry partners and } \\
\text { organizational roles, etc. }\end{array}$ \\
$\begin{array}{l}\text { To triangulate Delphi results } \\
\text { against specific relevant data, and } \\
\text { further explore some key leadership } \\
\text { issues }\end{array}$ \\
$\begin{array}{l}\text { Actionable } \\
\text { framework }\end{array}$ & $\begin{array}{l}\text { Drawing on all aspects of the study, a } \\
\text { more actionable leadership framework } \\
\text { was developed }\end{array}$ & $\begin{array}{l}\text { To develop a framework more } \\
\text { actionable and user friendly for the } \\
\text { industry partners }\end{array}$ \\
\hline
\end{tabular}

Table 4: Year 3 of the main study: The components and their rationales.

leadership issues previously identified. Taking all project results into account, a modified leadership framework was developed to be more actionable and user-friendly for the industry partners. These components and their rationales are briefly described in Table 4 .

It can be seen that the overall research project had many different components. Each of these, although foreshadowed in the grant application, was planned in more detail before implementation. In many instances it was then further modified in response to what eventuated. In the remainder of this article we identify some of the ways in which we used the meta-methodological features of action research to integrate the research elements and to fine-tune the components and subcomponents of the project.

\section{The Contribution of Action Research-Some Examples}

As mentioned previously, the nested character of the iterative action research cycle allows it to operate at any scale, from overall project (and beyond) to the moment-by-moment facilitation of one of a project's subcomponents. At the largest scale, almost all studies are built to some extent on the foundation of prior experience and perhaps the literature. At a finer grain, implementation of a research plan requires interaction between research stakeholders, who are work together.

To illustrate, following we provide some examples on different scales, from largest to smallest. We begin by describing the contribution of the likely to adjust their actions as they meta-methodology to the functioning of our research team. We then describe some of the ways in which the main study drew on the experience of the pilot study. We follow this up with some examples at mid-scale and below, applying to components or subcomponents. We conclude with a consideration of the benefits of the iterative nature of some of the components.

\section{Overall}

As mentioned, the research team was diverse. Different languages and terminologies, and different assumptions about research, could potentially have undermined our work. Throughout the study, our action research orientation helped us to make our diversity a benefit. In striving to be participative and collaborative we met often, faceto-face or by Skype or teleconference, and learned from one another. Driedger, Gallois, Sanders, and Santesso (2006) commented similarly on their use of convergent interviewing. Their regular collaborative meetings (a component of convergent interviewing) helped their research team find common ground despite their differences.

As a meta-methodology, action research let us learn how to interact with each other because, by nature, the method was interactive and 
longitudinal. Our diverse experience allowed us to devise effective processes at each stage of the research and to adapt them as required. In developing a model we could all be comfortable with we increased the likelihood that other users, too, would find it congenial and usable.

In the pilot study the research team (as it was at that time) developed a leadership framework for leadership in faith-based, not-for-profit organizations, especially for the one industry partner represented on the team. During the pilot study the team members found constructive ways to reconcile their different views of research, and learned to appreciate what each could offer. Those of us not already familiar with the challenges facing the aged care and community sector learned more about them. More directly, the pilot study was the foundation on which the grant application was assembled and the components of the main study were initially designed.

For example, we knew from the pilot study that the aged and community care sector faces severe challenges now and in the near future. It seemed unlikely that current approaches in the sector would be adequate for the future. We therefore began the main study with workshops during which participants from the industry partners studied realistic and likely near-future scenarios of what confronted the industry. On this basis they identified the leadership capabilities they believed the industry partners would most require.

The required outcomes from the research also changed as we met together to review the research. At several stages during the research we thought our partners needed tangible outputs such as a training manual. As the study progressed we learned that they really wanted an evidence-based approach to leadership development that included selection, development, and retention strategies.

Despite earlier comments in this article, we did conduct an initial literature review to prepare the ARC grant proposal. In addition, on two occasions, we revisited the literature in response to our emergent research findings. Just before the email survey we sought relevant literature to identify definitions of leadership styles. We questioned which of these the survey respondents favored. Later in the study we conducted a systematic literature review on the leadership development strategies that actually worked in the contexts we were researching. Unlike a traditional literature review, this was used to answer specific questions, which arose during our study and were relevant to formulating our recommendations.

Although we set out to test the leadership framework that we had developed in the pilot, eventually this framework played only a small role in our journey toward useful research outcomes. Although we referred to it in our team discussions, it was only used once during our interventions, and that was as an addition to the intervention. The original framework did help conceptualize the final framework in some ways. For the most part, though, the final framework was developed collaboratively by the research team in partnership with our key stakeholders. Thus, value from the research was co-created. The project was shaped in a cyclical manner as many complex projects are (Miller \& Lessard, 2007).

\section{Between and Within Components}

At a component level, each component was designed taking into account all that had been found previously, in the pilot or main study. Sometimes we did this by seeking to expand or refine the information provided by previous elements of the study. For example, the questions in the email survey and (later) in the Delphi survey were informed by what we knew from the pilot study and the scenario-based workshops. Similarly, the questions put to the workshop participants in the final focus groups were intended to provide more detail of some leadership capabilities identified as important earlier

Alternatively, sometimes the design was required to respond to unexpected events that impinged on the study. For example, the large-sample email survey of Year 1 was intended to check the generalizability of the more specific data gleaned from the industry partners. However, the response rate for the survey was lower than expected. Consequently, we felt constrained to interpret the responses with greater caution than would otherwise have been possible. To compensate for this to some extent, we extended the Delphi survey that followed it. We added questions. We included participants from outside the industry partners, and made a special effort to secure a good response rate. We also conducted further analyses of the Delphi survey data than we had originally planned. The Delphi survey became a more important part of the study than we had originally envisaged.

On a more detailed level, the person facilitating a workshop must often be responsive to what happens-going with the flow, as some describe it (e.g., Hogan, 2002). Thus, in the final workshop, small groups were tentatively formed. Participants were then asked to check that the groups were as diverse as possible, and then if necessary to exchange participants between groups to maximize the diversity. In the same workshops, participant responses to each segment were captured on an electronic whiteboard. When a participant gave too long a response to capture easily, the facilitator asked "Can you summarize that for me in six words?"

\section{Iterative Processes}

Of the explicitly iterative processes used, the convergent interviewing in the pilot study provides a clear example. Each of the 18 interviews began similarly with a question about the challenges facing not-for-profit organizations. After a few interviews, this question was modified by asking for the "most important challenges," to increase the focus of 
Value Co-creation with Stakeholders Using Action Research as a Meta-methodology in a Funded Research Project

the responses. Similar fine-tuning was performed on the other preplanned questions.

Equally important were the probe questions developed as the interviews proceeded. Their purpose was to increase the precision of the questioning, and therefore of the information collected. For example, when two or more interviews yielded an agreement about a theme, a probe question was devised asking for exceptions. On the other hand, when interviewees gave conflicting responses, a probe question asked for explanations of the disagreement. In effect, the interviewees were involved in interpreting the data that they and others had provided. The probe questions were sometimes designed between interviews, to prepare for the next one. Sometimes an alert interviewer was able to develop a probe on the run in immediate response to an answer from the interviewee.

The two-stage email Delphi survey in Year 2 of the main study constitutes an additional example. In the first round, participants were asked to provide answers to open-ended questions. In the second round, all first-round responses were emailed to the participants. They were then asked to identify the most important of those. For example, the first question in each round asked "What are the five most essential capabilities for a person to have if they are to provide effective leadership within your present organization?" In the second round, participants chose their five preferred responses to this question from the list of all responses previously provided.

This is worth exploring in a little more detail, as it illustrates both the commitment to participation and action, and the benefits of the iterative process. In the first round, the questions were open-ended so that the participants were free to provide their own answer to each question. Each of the collated responses sent to each participant in the second round was in the words of the person providing it. The final impor- tance of an item was therefore decided by summing the responses of participants. In other words, the participants provided both the wording of the items, and their perceived importance. The two-stage process allowed this level of participant involvement to be achieved.

The literature on facilitation attests to the commonness of iteration. Authors, such as Kaner (2007), describe iteration between divergent elements when ideas are generated and convergent elements when ideas are ranked or analyzed or otherwise used to make decisions. In both the pilot and major studies reported here, our workshop processes also used iterative components. In the final focus groups, for example, there were multiple questions. For each question, the procedure cycled through three components. Each participant was given individual thinking time, so that he or she could identify his or her response before he or she heard from others. Small groups then pooled the responses, and agreed on the order of importance. In the large group, each small group in turn then contributed one item not already recorded until a list of the most important items was constructed.

\section{Conclusion}

Research often develops in phases. In much current action research there is an emphasis on the "orientation" or "approach" - in effect the values-more than the cyclic process. We don't wish to de-emphasize the importance of the participatory aspects of action research, or the pursuit of actionable theory and its implementation. The orientation was important to the research team in this project. A commitment to participation guided our wish that our partners from the faith-based, not-for-profit organizations be equal partners in the decision-making process. Our commitment to collaboration helped us to deal constructively with the differences of opinion that arose within the research team. In fact, we believe that those differences contributed to the innovation in our approach and the richness of our findings. Our commitment to actionable outcomes guided us toward goals which were beneficial for the industry partners and usable by them.

But we needed more than that. We had to deal with contrasting demands. Funding bodies and ethics committees favored preplanning. Our stakeholders preferred to know what was ahead. The complexity of the research situation demanded flexibility. We needed the ability to respond to the demands of the moment as the research unfolded and our understanding grew. In managing the potentially conflicting demands, we were helped by utilizing the process of action research as a metamethodology-the cycles of planning, action, and reflection, and the nesting of those cycles to provide flexibility at all scales from largest to smallest, allowed the complexity of our research study to be more successfully managed. A similar approach may be relevant to the project management of other complex projects.

This article reported on the successful application of action research as an overarching methodology to collaboratively manage and deliver desired outcomes to its external and internal stakeholders in a large externally funded research project. It was not intended to be an article reporting on the actual research, rather an example of the benefit of using action research as a meta-methodology or a process to steer (govern) a funded research project.

The research resulted in the following benefits to stakeholders:

1. While meeting the somewhat contradictory and evolving stakeholder demands, the project was completed in time, budget, and scope.

2. The study and approach resulted in joint publications and presentations by both academic researchers and practitioners linking theory and practice, which is one of the benefits of using action research.

The article also illustrated how the macro and micro cycles of action 
research worked in conjunction to provide the flexibility, which resulted in a responsive research process that kept the project moving ahead despite changing directions to deliver desired outcomes.

\section{Acknowledgments}

The study to which this article relates was funded by a grant from the Australian Research Council's Linkage Program. The research team included researchers from Southern Cross University (SCU), the University of Technology Sydney (UTS), University of Southern Queensland (USQ), and Industry Partners Lutheran Community Care (LCC) and Baptist Community Services (BCS). An earlier developmental version of this article was presented at the Research and Research Methods Track of the 14th EURAM conference held at Valencia, Spain from June 4-7, 2014 to seek feedback.

The authors would like to thank the anonymous reviewers of the EURAM conference and the Project Management Journal for their valuable comments, which helped in improving this article considerably. Permission has been obtained from EURAM to publish the article in this journal.

\section{References}

Attwater, R. (2014). Meta-methodology. In D. Coghlan \& M. Brydon-Miller, SAGE encyclopedia of action research, (pp. 532-534). London, England: Sage.

Bhargava, S. (2013). Generic ways to improve SQA by meta-methodology for developing software projects. International Journal of Engineering Research and Applications, 3(4), 927-932.

Burns, D. (2007). Systemic action research: A strategy for whole system change. Bristol, England: Policy Press.

Cartwright, C., Sankaran, S., \& Kelly, J. (2008, June). Developing a new leadership framework for not-for-profit health and community care organisations in Australia. Report to Southern Cross
University (SCU) Graduate Research College (ASLaRC Edition), Retrieved from http://scu.edu.au/health-sciences/ index.php/181/

Cartwright, C., Shaw, K., Banbury, A., Sankaran, S., Craig, J., Soar, J., Kelly, J., Morgan, A., Sibley, A., Dick, B., Davies, A., Vindin, B., \& Ryan, N. (2013). An innovative model of leadership development for the not-for-profit aged and community care sector. Report to the Australian Research Council, Lutheran Community Care and Baptist Community Services, Retrieved from http://scu.edu.au/health-sciences/index .php/181/

Checkland, P. (1981). Systems thinking, systems practice. Chichester, England: Wiley.

Davis, J. (2004). Writing an action research thesis: One researcher's resolution of the problematic of form and process. In E. McWilliam, S. Danby, \& J. Knight (Eds.), Performing educational research: Theories, methods and practices (pp. 15-30). Teneriffe, Qld: Post Pressed.

Delbecq, A., Van de Ven, A., \& Gustafson, D. (1986). Group techniques for program planning (2nd ed.). Middleton, WI: Greenbriar.

Deming, W. E. (1986). Out of the crisis. Cambridge, MA: MIT Centre for Advanced Engineering Study.

Dick, B. (1990). Convergent interviewing, (3rd ed.) Brisbane, Queensland, Australia: Interchange.

Driedger, M., Gallois, C., Sanders, C., \& Santesso, N. (2006). Finding common ground in team-based qualitative research using the convergent interviewing method. Qualitative Health Research, 16(8), 1145-1157.

Edson, M. C. (2012). A complex adaptive systems view of resilience in a project team. Systems Research and Behavioral Science, 29(5), 499-516.

Fisher, K., \& Phelps, R. (2006). Recipe or performing art? Challenging conventions for writing action research theses. Action Research, 4(2), 143-164.
Greenwood, D., \& Levin, M. (2006). Introduction to action research: Social research for social change (2nd ed.). Thousand Oaks, CA: Sage.

Guindon, R. (1990). Designing the design process: Exploiting opportunistic thoughts. Human-Computer Interaction, 5(2-3), 305-344.

Haynes, C. (2010). A case for flexible epistemology and metamethodology in religious fundamentalism research. Integral Review, 6(3), 36-56.

Hogan, C. (2002). Understanding facilitation: Theory and principles. London, England: Kogan Page.

Institute of Medicine. (2001). Improving the quality of long-term care. Washington, DC: National Academy of Sciences.

Jackson, M. (2003). Systems thinking: Creative holism for managers. Chichester, England: Wiley.

Kaner, S. (2007). Facilitator's guide to participatory decision-making, (2nd ed.). San Francisco, CA: Wiley.

Kemmis, S., \& McTaggart, R. (2005). Participatory action research. In N. Denzin \& Y. Lincoln (Eds.), The Sage handbook of qualitative research, (3rd ed.) (pp. 559-603). Thousand Oaks, CA: Sage.

Kemmis, S., McTaggart, R., \& Nixon, R. (2014). The action research planner: Doing critical participatory action research. Singapore: Springer.

Kolb, D. (1984). Experiential learning: Experience as the source of learning and development. Englewood Cliffs, NJ: Prentice-Hall.

Lewin, K. (1946). Action research and minority problems. Journal of Social Issues, 2(4), 34-46.

Lichtenstein, B., Uhl-Bien, M., Marion, R., Seers, A., Orton, J., \& Schreiber, C. (2006). Complexity leadership theory: An interactive perspective on leading in complex adaptive systems. Emergence: Complexity and Organization, 8(4), 2-12. Lingard, L., Albert, M., \& Levinson, W. (2013). Grounded theory, mixed methods, and action research. British Medical Journal, 337(7667), 459-461. 
Value Co-creation with Stakeholders Using Action Research as a Meta-methodology in a Funded Research Project

List, D. (2006). Action research cycles for multiple futures perspectives. Futures, 38(6), 673-684.

Lorenz, E. (1972). Predictability: Does the flap of a butterfly's wings in Brazil set off a tornado in Texas? Paper presented at the meeting of the American Association for the Advancement of Science, Washington, DC. Retrieved from http://eaps4.mit.edu/research /Lorenz/Butterfly_1972.pdf

Macaulay, A., Jagosh, J., Pluye, P., Bush, P., \& Salsberg, J. (2013). Quantitative methods in participatory research: Being sensitive to issues of scientific validity, community safety, and the academiccommunity relationship. Nouvelles Pratiques Sociales, 25(2), 159-172.

Miller, R., \& Lessard, D. (2007). Evolving strategy: Risk management and the shaping of large engineering projects. MIT Sloan Research Paper No. 4639-07, Retrieved from http://papers.ssrn.com /sol3/papers.cfm?abstract_id=962460\#\# OECD. (2005). OECD factbook: An essential tool for following world economic, social and environmental trends. Paris, France: OECD.

Patton, M. Q. (2011). Developmental evaluation: applying complexity concepts to enhance innovation and use. New York, NY: Guilford.

Peon-Escalante, I., Enrique, I., Aceves, F., \& Badillo, I. (2008). Systemic metamethodology for methods design. In J. Wilby (Ed.), Proceedings of the 52nd Annual Meeting of the ISSS, Madison WI. Retrieved from http://journals.isss .org/index.php/proceedings52nd /article/view/984/362

Phelps, R., \& Graham, A. (2010). Exploring the complementarities between complexity and action research: The story of Technology Together. Cambridge Journal of Education, 40(2), 183-197.

Pietroburgo, J., \& Wernet, S. P. (2010). Merging missions and methods: A study of restructuring and adaptation in nonprofit healthcare organizations. Journal of Healthcare Leadership, 2010(2), 69-81.
Raelin, J. A. (2004). Don't bother putting leadership into people. Academy of Management Executive, 18(3), 131-135.

Rampton, S., \& Stauber, J. (2002). Research funding, conflicts of interest, and the "meta-methodology" of public relations. Public Health Reports, 117(4), 331-339.

Reason, P., \& Bradbury, H. (2008). Introduction. In P. Reason \& H. Bradbury (Eds.), The Sage handbook of action research: Participative inquiry and practice (2nd ed.) (pp. 1-10). Los Angeles, CA: Sage.

Sankaran, S., \& Kumar, M. (2010, July 7-10). Implementing organizational change using action research in two Asian cultures. Proceedings of the Project Management Institute's Education and Research Conference, Washington, DC.

Schein, E. (1996). Kurt Lewin's change theory in the field and in the classroom: Notes towards a model of managed learning. Systems Practice, 9(1), 27-47.

Susman, G., \& Evered, R. (1978). An assessment of the scientific merits of action research. Administrative Science Quarterly, 23(4), 582-603.

White, K. R. J. (2014). Agile project management. In P. C. Dinsmore \& J. CabanisBrewin (Eds.), The AMA handbook of project management (4th ed.) (pp. 441-450). New York, NY: Amacom.

Windsor, L. (2013). Using concept mapping in community-based participatory research: A mixed methods approach. Journal of Mixed Methods Research, 7(3), 274-293.

Zuber-Skerritt, O., \& Perry, C. (2002). Action research within organisations and university thesis writing. The Learning Organization, 9(4), 171-179.

Bob Dick is an independent scholar, an occasional academic, and a freelance consultant in the fields of community and organizational change. In much of his current consulting he uses action learning for leadership development, cultural change, and organizational resilience using highly participative processes. Bob was a member of the steering committee for the research project described in this article and also facilitated all the focus groups and scenario analysis workshops for the project. He can be contacted at bd@bigpond.net.au

Shankar Sankaran is a Professor of Organisational Project Management at the University of Technology Sydney. He has published books, book chapters, journal articles, and has presented papers on the use of action research in business and management. He has successfully supervised doctoral students who have used action research. His own doctoral dissertation used action research and action learning to deliver a large-scale change in a project organization in Singapore. Shankar wants to motivate project management researchers to use translational and transformational methods to conduct their research and is one of the editors of a recently published book titled, Novel Approaches to Organizational Project Management Research: Translational and Transformational. Shankar was one of the chief investigators for the research project described in this article. He can be contacted at shankar.sankaran@uts.edu.au

Kelly Shaw is a public health physician, epidemiologist, and clinician. Kelly's areas of research interest are health policy, clinical pathways and models of care, service and program evaluation and public health. Kelly was one of the chief investigators for the research project described in this article. She can be contacted at kelly. shaw@kphealth.com.au

Jacqueline Kelly is an accomplished leader and strategist with a strong track record in creating healthy, sustainable, performance-oriented organizations. In her current role as Chief Executive Officer of Lutheran Community Care (LCC), Jacqueline establishes strategic direction with the board and manages day-to-day operations of one of Queensland's leading not-for-profit providers of aged care, family services, disability services, and hospital chaplaincy. In addition to her position as CEO of LCC, Jacqueline has served for many years as 
a member of the Board for Lutheran Aged Care Australia, was previously a representative on the National Aged Care Alliance (NACA), and is a Trustee of the Committee for Economic Development of Australia (CEDA). Jacqueline has more than 20 years of experience working across all sectors and a diverse range of industries, and has previously held senior executive roles in some of Australia's leading organizations, including Queensland Treasury, Queensland Investment Corporation, and Lend Lease Advisor Services. Jacqueline was one of the partner investigators for the research project described in this article. She can be contacted at Jacqueline.Kelly@|ccqld.org.au

Professor Jeffrey Soar holds the Personal Chair in Human-Centred Technology in the School of Management \& Enterprise; Faculty of Business, Education, Law \& Arts at the University of Southern Queensland Australia. His teaching and research is in technology innovation for business. He has attracted national and international research grants and has published over
150 peer-reviewed publications. Jeffrey was one of the chief investigators for the research project described in this article. He can be contacted at soar@usq.edu.au

Emeritus Professor Alan Davies has had a lifelong interest in building learning, personal development, and social development into the work and community organizational settings in which we spend much of our waking lives. He has found action research and open systems thinking useful in pursuing this interest. Emeritus Professor Davies has retired from Southern Cross University, Australia. He continues to do consulting work using action research and running large group intervention processes in organizations and communities. Alan was a member of the steering committee in the research project described in this article and helped plan and conducted an extensive modified Delphi study used in the project. He can be contacted at atdavies@bigpond.com

Annie Banbury has worked for 20 years in health promotion in the United Kingdom and Australia. She has worked across all topics and settings in a wide variety of roles, including, project management, strategic development, and as a consultant and lecturer. She moved into research in 2009 to lead on the qualitative component of the Mull Hypothesis Study, which was awarded Highly Commended in the National Drug and Alcohol Awards 2011. Since joining Aged Services Learning and Research Centre at Southern Cross University her research has focused on older people's issues. She is currently a PhD candidate with a scholarship from the Health CRN at CQUniversity. Her research focuses on telehealth and its application to health literacy, self-management skills, and social networks with older people living in the community with chronic conditions. Annie was involved as a project manager and research scholar for the research project described in this article and made a significant contribution to its final report. She can be contacted at annie. banbury@scu.edu.au 